\title{
Characterization of plasma proteins in children of different Mycobacterium tuberculosis infection status using label-free quantitative proteomics
}

\author{
Jieqiong $\mathrm{Li}^{1,2,3,4, *}$, Lin Sun ${ }^{1,2,3,4, *}$, Fang $\mathrm{Xu}^{1,2,3,4}$, Jing Xiao ${ }^{1,2,3,4}$, Weiwei Jiao ${ }^{1,2,3,4}$, Hui \\ $\mathbf{Q i}^{1,2,3,4}$, Chen Shen ${ }^{1,2,3,4}$ and Adong Shen ${ }^{1,2,3,4}$ \\ ${ }^{1}$ Beijing Key Laboratory of Pediatric Respiratory Infection Diseases, Beijing Pediatric Research Institute, Beijing Children's \\ Hospital, Capital Medical University, National Center for Children's Health, Beijing, China \\ ${ }^{2}$ National Clinical Research Center for Respiratory Diseases, Beijing, China \\ ${ }^{3}$ National Key Discipline of Pediatrics, Capital Medical University, Beijing, China \\ ${ }^{4}$ Key Laboratory of Major Diseases in Children, Ministry of Education, Beijing, China \\ * Co-authors \\ Correspondence to: Adong Shen, email: shenad16@hotmail.com \\ Keywords: plasma proteins, active tuberculosis (ATB), latent TB infection (LTBI), children, label-free quantitative proteomics \\ Received: July 20, $2016 \quad$ Accepted: July 29, $2017 \quad$ Published: September 23, 2017 \\ Copyright: Li et al. This is an open-access article distributed under the terms of the Creative Commons Attribution License 3.0 \\ (CC BY 3.0), which permits unrestricted use, distribution, and reproduction in any medium, provided the original author and source \\ are credited.
}

\section{ABSTRACT}

Tuberculosis (TB), caused by Mycobacterium tuberculosis (MTB), is an infectious disease found worldwide. Children infected with MTB are more likely to progress to active TB (ATB); however, the molecular mechanism behind this process has long been a mystery. We employed the label-free quantitative proteomic technology to identify and characterize differences in plasma proteins between ATB and latent TB infection (LTBI) in children. To detect differences that are indicative of MTB infection, we first selected proteins whose expressions were markedly different between the ATB and LTBI groups and the control groups (inflammatory disease control (IDC) and healthy control (HC) groups). A total of 521 proteins differed ( $>1.5$-fold or $<0.6$-fold) in the LTBI group, and $\mathbf{3 1 8}$ proteins in the ATB group when compared with the control groups. Of these, 49 overlapping proteins were differentially expressed between LTBI and ATB. Gene Ontology (GO) analysis revealed most proteins had a cellular and organelle distribution. The MTB infection status was mainly related to differences in binding, cellular and metabolic processes. XRCC4, PCF11, SEMA4A and ATP11A were selected and further verified by qPCR and western blot. At the mRNA level, the expression of XRCC4, PCF11and SEMA4A presented an increased trend in ATB group compare with LTBI. At the protein level, the expression of all these proteins by western blot in ATB/LTBI was consistent with the trends from proteomic detection. Our results provide important data for future mechanism studies and biomarker selection for MTB infection in children.

\section{INTRODUCTION}

Tuberculosis (TB), caused by Mycobacterium tuberculosis (MTB), continues to be a serious infectious disease worldwide [1,2]. It is estimated that most active TB (ATB) cases originate from an initial latent TB infection (LTBI), a state without any clinical symptoms, radiological abnormality, and microbiological evidence. In contrast to adults, young children infected with MTB are more likely to progress to ATB within the first year of primary infection; however, the molecular mechanisms behind this have long been a mystery [3].

MTB infection alters the expression of TBassociated proteins, which are released into the bloodstream through different pathways [4]. Thus, analysis of TB-associated proteins in patients with different MTB infection status might reflect the mechanism of MTB infection and progression. Plasma proteins, 
Table 1: Demographic characteristic of the participants

\begin{tabular}{|c|c|c|c|c|}
\hline Characteristics & ATB & LTBI & IDC & HC \\
\hline Sample size & 19 & 16 & 17 & 20 \\
\hline Age (years) ${ }^{\mathrm{a}}$ & $6.8 \pm 5.1$ & $7.2 \pm 3.2$ & $6.9 \pm 4.7$ & $7.4 \pm 3.5$ \\
\hline Age range (years) & $0.2-16$ & $3-11$ & $0.8-15.3$ & 4-14 \\
\hline Gender (Male/Female) & $10 / 19$ & $8 / 16$ & $9 / 17$ & $9 / 20$ \\
\hline BCG vaccine & $19 / 19$ & $16 / 16$ & $17 / 17$ & $20 / 20$ \\
\hline
\end{tabular}

${ }^{a}$ Data are presented as the mean $\pm \mathrm{SD}$.

such as cytokines, extracellular secretory proteins, and other soluble factors involved in the immune system, are reported to be associated with the pathogenesis of infectious disease [5]. For instance, Shuxian Li et al. revealed that the proteins secreted by A549 cells were associated with the infection of Mycoplasma pneumoniae [6]. Dandan Xu and her colleagues found that the level of serum proteins (S100A9, SOD3, and MMP9) in ATB reflected the immune response to the MTB infection [5]. Together, the above information implies an important role for proteins in host-pathogen interactions.

Recently, advances in comprehensive analytical techniques, such as proteomics, make the analysis of all plasma proteins possible [7]. Proteomic analysis using the label-free quantitative protocol is a novel approach for high throughput analysis, which provides for a rapid comparison of proteins. Given that a specific mixture of plasma proteins has distinctive characteristics, this technique has been used to investigate the proteomic patterns in many diseases, including infectious diseases [8-11], vascular diseases [12-14] and cancer [15]. Thus, analysis of the expression of TB-associated proteins in plasma could provide a better understanding of conversion from LTBI to ATB in children.

Therefore, this study aimed to characterize the plasma proteins in children of different MTB infection status by label-free quantitative proteomics. We observed that 49 proteins were differentially-expressed in the LTBI and ATB groups, and a subset was validated using quantitative real-time PCR (qPCR) and western blotting. Our results will provide insight into the mechanism of MTB infection and progression, as well as potential biomarker selection for the diagnosis of ATB in children.

\section{RESULTS}

\section{Clinical characteristics}

The demographic characteristics of participants showed no obviously differences between groups (Table 1 ; age, $P=0.625$; gender, $P=0.318$ ). Among the 19 children in the ATB group, 12 had pulmonary TB, three had tubercular meningitis, one had bone tuberculosis and three had systemic tuberculosis. Among the 17 children in the IDC group, 10 had pneumonia (including both bacterial and viral infections), and seven children had upper respiratory tract infections. Furthermore, the children in inflammatory disease control (IDC) and healthy control (HC) groups had negative interferon gamma release assay (IGRAs) and tuberculin skin test (TST) results, without a history of ATB. All the subjects were vaccinated with BCG.

\section{Label-free quantitative proteomics analysis of the differences between ATB and LTBI}

As respiratory infections are often present in children who have ATB or LTBI, both IDC and HC groups were included in this proteomics analysis. Based on the high throughput proteomics data, a total of 2170 proteins were identified. The plasma, pooled for each group was divided into 3 samples and each liquid chromatographymass/mass spectrometry (LC-MS/MS) analysis was repeated 3 times.

To detect the proteins that are indicative of MTB infection, we first selected specific proteins whose expression was markedly different between the ATB and control (IDC and HC) groups, and between the LTBI groups and control (IDC and HC) groups. As shown in Figure 1, a total of 318 proteins differed in the ATB group, and 521 proteins in the LTBI group $(>1.5$ fold or $<0.6$ fold) when compared with the HC and IDC groups. Of these proteins associated with MTB infection, 49 proteins were differentially expressed between ATB and LTBI. Specifically, 41 proteins were up-regulated ( $>1.5$ fold) and 8 proteins were down-regulated $(<0.6$ fold) in the ATB group compared with the LTBI group (Table 2).

To reveal the relationship between the 49 different proteins, a hierarchical clustering based on Pearson correlation of variances was applied using R studio. Figure 2A depicts hierarchical clustering of the 49 identified proteins, where an increasingred color indicates increasing protein expression levels. Thus, the most prominent area of up-regulation in ATB subjects was seen in the region where these protein peaks are shown in red. Furthermore, important features were selected by a volcano plot (Figure 2B). 


\section{Gene ontology analysis of the identified proteins}

To further understand the functions of these identified proteins, we classified the 49 differential proteins between LTBI and ATB by their Gene Ontology (GO) categories, including cellular component (CC), molecular function (MF), and biological process (BP) using the Web Gene Ontology Annotation Plotting (WEGO, Figure 3, Supplementary Table 1 and 2). According to the analysis of $\mathrm{CC}$, the majority of the proteins had a cell and organelle distribution. According to the analysis of BP, the primary functions were cellular processes, metabolic processes and biological regulation; while others were related to cellular component organization, pigmentation, multicellular organismal processes and so on. According to the analysis of MF, these proteins could be classified into eight categories as follows: molecular transducer activity, translation regulator activity, enzyme regulator activity, transcription regulator activity, structural molecule activity, catalytic activity, binding, transporter activity. Among them, a large proportion had binding as a molecular function. To identify the most important proteins involved in the conversion from LTBI to ATB, proteins that were obviously up or down-regulated should be categorized into many different functional groups.

\section{KEGG enrichment analysis of the identified proteins}

KEGG enrichment analysis was then implemented to test enrichment of the proteomics pathways between the LTBI and ATB groups. The results indicated that mRNA surveillance pathway $(P=0.018)$, Non-homologous endjoining $(P=0.034)$ and Spliceosome $(P=0.040)$, One

A ATB vs. HC ATB vs. IDC

B LTBI vs. HC LTBI vs. IDC

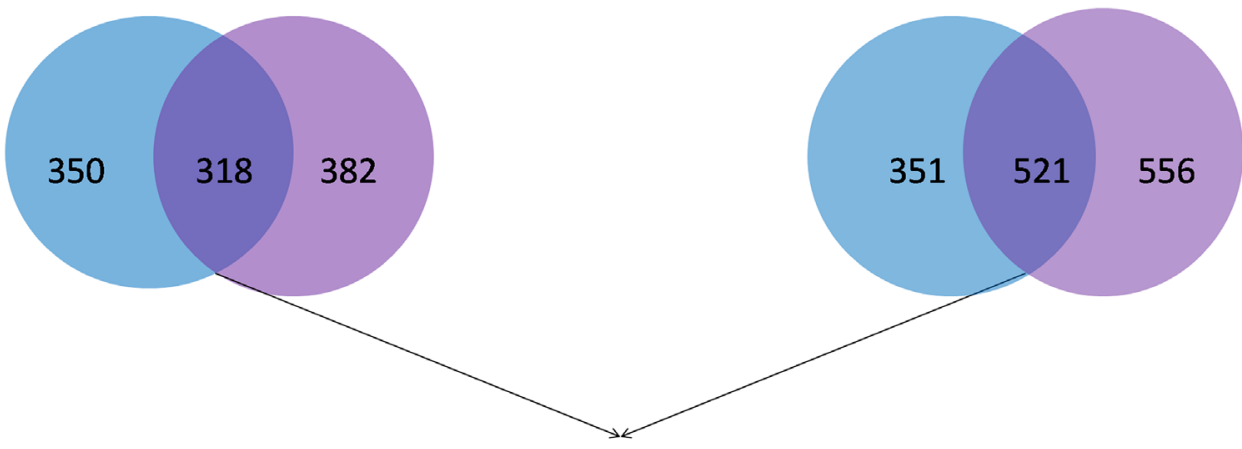

C ATB vs. HC-IDC LTBI vs. HC-IDC

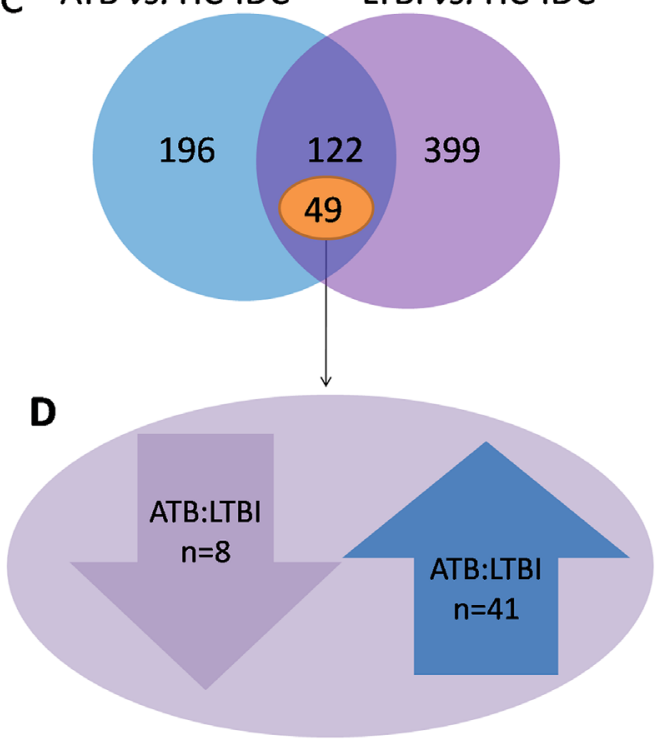

Figure 1: Different proteins selected through LC-MS/MS analysis. (A) 318 proteins were significantly different in ATB subjects compared with the HC and IDC groups. (B) 521 proteins were significantly different in LTBI subjects compared with the HC and IDC groups. (C) Among these protein, 49 proteins were markedly different between ATB and LTBI. (D) 41 proteins were up-regulated (>1.5 fold) and 8 proteins were down-regulated $(<0.6$-fold) in the ATB group compared with the LTBI group. 
Table 2: Differentially expressed proteins identified following LC-MS/MS of ATB and LTBI plasma fractions

\begin{tabular}{|c|c|c|c|c|c|c|}
\hline Gi number & Protein name & Gene & Uniprot Identifier & mass & pI & ATB:LTBI \\
\hline gi|282165800 & tight junction protein $\mathrm{ZO}-2$ isoform 5 & TJP2 & B7Z2R3 & 115.10 & 6.30 & $\downarrow$ \\
\hline gi|6912752 & zinc finger protein 281 & ZNF281 & Q9Y2X9 & 96.90 & 9.50 & $\downarrow$ \\
\hline gi|122114658 & hypothetical protein LOC23053 & ZSWIM8 & A7E2V4 & 197.70 & 6.40 & $\downarrow$ \\
\hline gi|310110387 & $\begin{array}{l}\text { PREDICTED: hypothetical protein } \\
\text { LOC100508795 }\end{array}$ & - & - & 13.60 & 10.80 & $\downarrow$ \\
\hline gi|296317364 & $\begin{array}{l}\text { testis-specific serine/threonine-protein } \\
\text { kinase } 4 \text { isoform } 1\end{array}$ & TSSK4 & Q6SA08 & 38.40 & 9.60 & $\downarrow$ \\
\hline gi|113722125 & $\begin{array}{l}\text { type II inositol-1,4,5-trisphosphate } \\
5 \text {-phosphatase precursor }\end{array}$ & INPP5B & P32019 & 103.90 & 5.10 & $\downarrow$ \\
\hline gi|40556393 & protein Jade-1 long isoform & JADE1 & Q6IE81 & 95.50 & 9.20 & $\downarrow$ \\
\hline gi|20149540 & $\begin{array}{l}\text { protein-lysine } 6 \text {-oxidase isoform } 1 \\
\text { preproprotein }\end{array}$ & LOX & P28300 & 46.90 & 9.10 & $\downarrow$ \\
\hline gi|24308211 & integrator complex subunit 2 & INTS2 & Q9H0H0 & 134.30 & 5.70 & $\uparrow$ \\
\hline gi|105990532 & apolipoprotein B-100 precursor & APOB & P04114 & 515.20 & 6.60 & $\uparrow$ \\
\hline gi|140161498 & $\begin{array}{l}\text { microtubule-associated tumor } \\
\text { suppressor candidate } 2 \text { isoform a }\end{array}$ & MTUS2 & Q5JR59 & 151.10 & 6.30 & $\uparrow$ \\
\hline gi|33356174 & pinin & PNN & Q9H307 & 81.60 & 6.80 & $\uparrow$ \\
\hline gi|169169660 & $\begin{array}{l}\text { PREDICTED: hypothetical protein } \\
\text { LOC100131673 }\end{array}$ & - & - & 50.80 & 9.40 & $\uparrow$ \\
\hline gi|110611228 & utrophin & UTRN & P46939 & 394.20 & 5.10 & $\uparrow$ \\
\hline gi|28872812 & $\begin{array}{l}\text { MORC family CW-type zinc finger } \\
\text { protein } 3\end{array}$ & MORC3 & Q14149 & 107.00 & 5.30 & $\uparrow$ \\
\hline gi|32307152 & oxytocin receptor & OXTR & P30559 & 42.70 & 10.90 & $\uparrow$ \\
\hline gi|38016914 & $\begin{array}{l}\text { SAM domain and HD domain- } \\
\text { containing protein } 1\end{array}$ & SAMHD1 & Q9Y3Z3 & 72.20 & 6.80 & $\uparrow$ \\
\hline gi|21361912 & $\begin{array}{l}\text { dnaJ homolog subfamily } \mathrm{C} \text { member } 1 \\
\text { precursor }\end{array}$ & DNAJC1 & Q96KC8 & 63.80 & 9.40 & $\uparrow$ \\
\hline gi|157266264 & $\begin{array}{l}\text { pleckstrin homology-like domain } \\
\text { family B member } 3\end{array}$ & PHLDB3 & Q6NSJ2 & 71.90 & 6.10 & $\uparrow$ \\
\hline gi|4504445 & $\begin{array}{l}\text { heterogeneous nuclear } \\
\text { ribonucleoprotein } \mathrm{A} 1 \text { isoform a }\end{array}$ & HNRNPA1 & P09651 & 34.20 & 9.70 & $\uparrow$ \\
\hline gi|148806908 & $\begin{array}{l}\text { fibronectin type III domain-containing } \\
\text { protein } 1\end{array}$ & FNDC1 & Q4ZHG4 & 205.40 & 9.80 & $\uparrow$ \\
\hline gi|303304991 & $\begin{array}{l}\text { centrosomal protein of } 152 \mathrm{kDa} \\
\text { isoform } 1\end{array}$ & CEP152 & O94986 & 195.50 & 5.30 & $\uparrow$ \\
\hline gi|222136639 & $\begin{array}{l}\text { C-1-tetrahydrofolate synthase, } \\
\text { cytoplasmic }\end{array}$ & MTHFD1 & P11586 & 101.50 & 7.00 & $\uparrow$ \\
\hline gi|59710085 & hypothetical protein LOC146562 & C16orf71 & Q8IYS4 & 55.60 & 4.70 & $\uparrow$ \\
\hline gi|291045249 & $\begin{array}{l}\text { collagen alpha-1(XIII) chain } \\
\text { isoform } 19\end{array}$ & COL13A1 & Q5TAT6 & 59.40 & 9.90 & $\uparrow$ \\
\hline gi|54112117 & splicing factor $3 \mathrm{~B}$ subunit 1 isoform 1 & SF3B1 & O75533 & 145.70 & 6.70 & $\uparrow$ \\
\hline
\end{tabular}

(Continued) 


\begin{tabular}{|c|c|c|c|c|c|c|}
\hline Gi number & Protein name & Gene & Uniprot Identifier & mass & pI & ATB:LTBI \\
\hline gi|31377667 & lon protease homolog 2 , peroxisomal & LONP2 & Q86WA8 & 94.60 & 7.00 & $\uparrow$ \\
\hline gi|7949031 & cytochrome P450 2B6 & CYP2B6 & P20813 & 56.20 & 9.10 & $\uparrow$ \\
\hline gi|51702222 & protein SPT2 homolog & SPTY2D1 & Q68D10 & 75.60 & 10.30 & $\uparrow$ \\
\hline gi|150421681 & $\begin{array}{l}\text { probable phospholipid-transporting } \\
\text { ATPase IH isoform b }\end{array}$ & ATP11A & P98196 & 135.80 & 6.30 & $\uparrow$ \\
\hline gi| 55741447 & $\begin{array}{l}\text { pleckstrin homology domain- } \\
\text { containing family H member } 1\end{array}$ & PLEKHH1 & Q9ULM0 & 151.10 & 9.00 & $\uparrow$ \\
\hline gi|33620745 & $\begin{array}{l}\text { pre-mRNA cleavage complex } 2 \\
\text { protein Pcf11 }\end{array}$ & PCF11 & O94913 & 172.90 & 9.30 & $\uparrow$ \\
\hline gi|38027923 & COP9 signalosome complex subunit 5 & COPS5 & Q92905 & 37.60 & 6.10 & $\uparrow$ \\
\hline gi|45827701 & protein dopey-2 & DOPEY2 & Q9Y3R5 & 258.10 & 5.90 & $\uparrow$ \\
\hline gi|118421085 & treslin & TICRR & Q7Z2Z1 & 210.70 & 9.80 & $\uparrow$ \\
\hline gi|113416493 & $\begin{array}{l}\text { PREDICTED: putative TAF11-like } \\
\text { protein ENSP00000332601-like }\end{array}$ & - & - & 21.60 & 7.70 & $\uparrow$ \\
\hline gi|159032029 & sentrin-specific protease 5 & SENP5 & Q96HI0 & 86.60 & 10.10 & $\uparrow$ \\
\hline gi|28827774 & $\begin{array}{l}\text { dual specificity tyrosine- } \\
\text { phosphorylation-regulated kinase } 4\end{array}$ & DYRK4 & Q9NR20 & 59.60 & 9.70 & $\uparrow$ \\
\hline gi|40804748 & $\begin{array}{l}\text { LIM and senescent cell antigen-like- } \\
\text { containing domain protein } 2 \text { isoform } 2\end{array}$ & LIMS2 & Q7Z4I7 & 41.50 & 10.10 & $\uparrow$ \\
\hline gi|5454058 & $\begin{array}{l}\text { CMP-N-acetylneuraminate- } \\
\text { beta-galactosamide-alpha-2,3- } \\
\text { sialyltransferase } 4\end{array}$ & ST3GAL4 & Q11206 & 37.40 & 10.00 & $\uparrow$ \\
\hline gi|19923437 & $\begin{array}{l}\text { GTP:AMP phosphotransferase, } \\
\text { mitochondrial }\end{array}$ & AK3 & Q9UIJ7 & 25.50 & 9.50 & $\uparrow$ \\
\hline gi|50659100 & $\begin{array}{l}\text { inactive serine protease PAMR1 } \\
\text { isoform } b\end{array}$ & PAMR1 & Q6UXH9 & 80.10 & 8.80 & $\uparrow$ \\
\hline gi|4507945 & DNA repair protein XRCC4 isoform 1 & $\mathrm{XRCC} 4$ & Q13426 & 38.00 & 4.80 & $\uparrow$ \\
\hline gi|164519084 & rab GTPase-activating protein 1 & RABGAP1 & Q9Y3P9 & 121.70 & 5.00 & $\uparrow$ \\
\hline gi|98986457 & host cell factor 1 & HCFC1 & P51610 & 208.60 & 7.90 & $\uparrow$ \\
\hline gi|310123245 & $\begin{array}{l}\text { PREDICTED: Golgin subfamily A } \\
\text { member 8-like protein 2-like, partial }\end{array}$ & - & - & 62.60 & 6.20 & $\uparrow$ \\
\hline gi|300863076 & semaphorin-4A isoform 2 & SEMA4A & Q9H3S1 & 69.10 & 6.30 & $\uparrow$ \\
\hline gi|310113571 & $\begin{array}{l}\text { PREDICTED: hypothetical protein } \\
\text { LOC100508805 }\end{array}$ & - & - & 68.60 & 6.60 & $\uparrow$ \\
\hline gi $\mid 46409310$ & zinc finger protein 467 & ZNF467 & Q7Z7K2 & 65.10 & 11.00 & $\uparrow$ \\
\hline
\end{tabular}

carbon pool by folate $(P=0.049)$ were significantly associated with the conversion from LTBI to ATB (Figure 4 and Supplementary Table 3).

\section{Validation of proteomic results}

Proteins identified as differentially expressed in ATB and LTBI patients were validated using $\mathrm{PPCR}$ and western blotting. Among the 49 different proteins, four
(XRCC4, PCF11, SEMA4A and ATP11A) were selected for further verification. The selection of the proteins for the verification stage was based on the following criteria: (1) high fold change; (2) being representative of the 49 different proteins; (3) $P$ value of $<0.05$ in KEGG analysis (XRCC4 and PCF11) or having biological functions associated with immunity and other infectious diseases (SEMA4A and ATP11A). Although these four proteins were mainly distributed in cellular parts, their functions 
were different. Most proteins different between the ATB and LTBI groups were related to binding, cellular and metabolic process and these four selected proteins were associated with these processes. Firstly, the four selected proteins all were also participate in the binding processes, including nucleic acid binding and protein binding. Additionally, XCRR4 and PCF11 had an effect on metabolic process while SEMA4A and ATP11A were related to the cellular process. Thus, these four proteins, being representative of the 49 different proteins, reflected the different status of MTB infection.

At the mRNA level, the expression of XRCC4, PCF11and SEMA4A presented an increased trend in ATB group compare with that in LTBI and this agreed with the
A

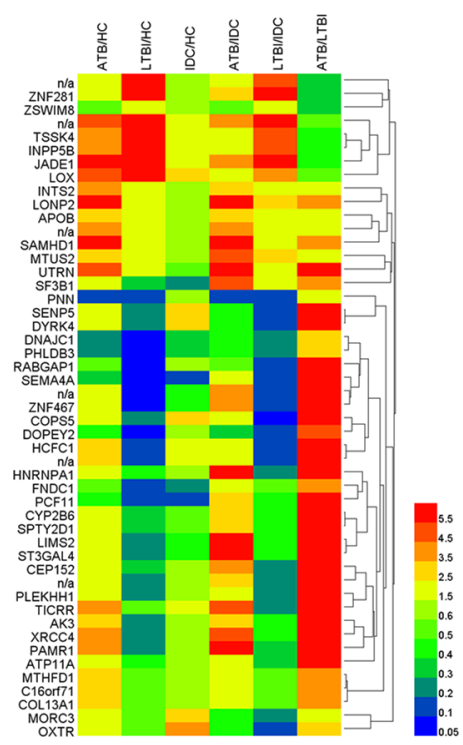

B

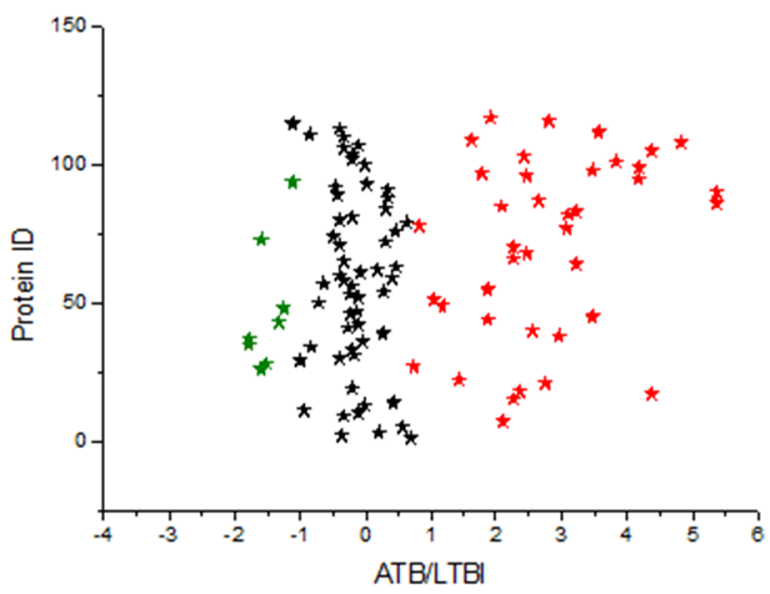

Figure 2: Heat map and volcano plot of the 49 identified proteins. (A) The most striking area of up-regulation in ATB patients is seen in the region where a series of protein peaks are shown in red. (B) Important features selected by volcano plot.

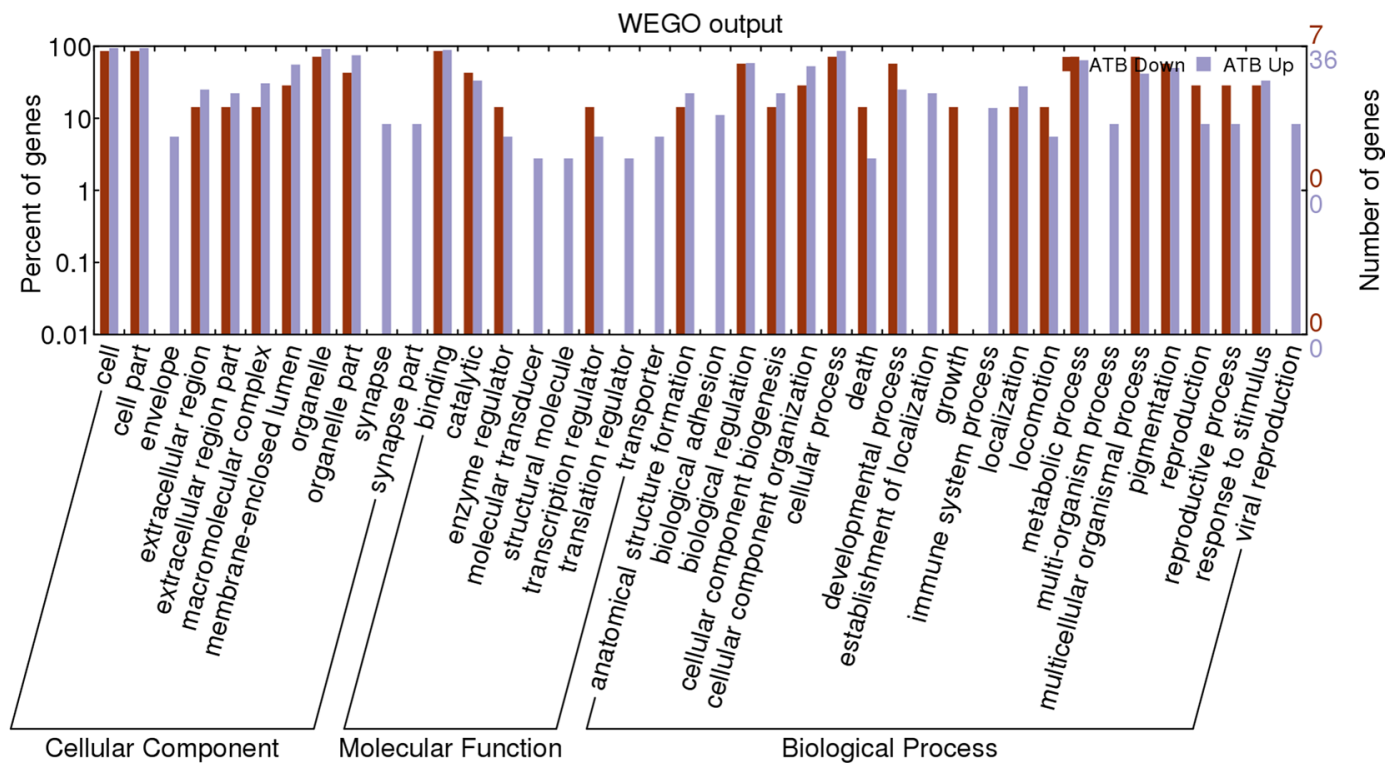

Figure 3: Web Gene Ontology Annotation Plot (WEGO) classification of differentially expressed proteins by labelfree quantitative proteomics experiments between ATB and LTBI. The differentially expressed proteins are grouped into three hierarchically structured terms: biological process, cellular component, and molecular function. 
proteomic results. The ratio of ATP11A was apparently inconsistent with the proteomic data (Figure 5A). The mRNA result implies that regulation is occurring at the point of protein translation, not gene transcription. At the protein level, our results demonstrated that the plasma levels of XRCC4, PCF11, SEMA4A and ATP11A in the ATB group were significantly higher than the LTBI group (all $P$ $<0.05$; Figure 5B). Representative western blots are shown in Figure $5 \mathrm{C}$. These ratios were consistent with the trends of proteomics results. Total protein staining by Coomassie Blue employed as the loading control (Figure 5D).

\section{DISCUSSION}

It is generally known that the immune response induced by MTB infection influences the pathogenic mechanisms and protein expression [16]. Specifically, TBassociated proteins appear in the circulation by a variety of mechanisms, including direct secretion of proteins, stimulated production of reactive proteins, or production of proteins during the infection of the MTB $[17,18]$. Accurate detection TB-associated proteins lead to a better understanding of the mechanism of MTB infection and progression.

Plasma proteins including cytokines, extracellular secretory proteins, growth factors, and other soluble factors, contribute to many physiological processes. Recently, researchers have demonstrated that proteins are also significantly associated with different diseases. For instance, the secretion of adiponectin is associated with the development of many cardiovascular related diseases [19]. Similarly, plasma proteins also have profound effects on a variety of infectious diseases. For example, during herpes simplex virus 1 (HSV-1) infection, increased IFNinduced protein expression is reported to play an essential role in extracellular antiviral functions [20]. Similarly, the secretion of proteins may increase the number of $\mathrm{CD}^{+}$ $\mathrm{T}$ cells [21]. Taken together, the above data show the importance of plasma proteins during pathogen infection.

This study demonstrated a difference in plasma protein pattern in MTB infection in children. As respiratory infections are often present in children who have ATB or LTBI, we included both IDC and HC groups in this proteomic analysis. To detect differences that are

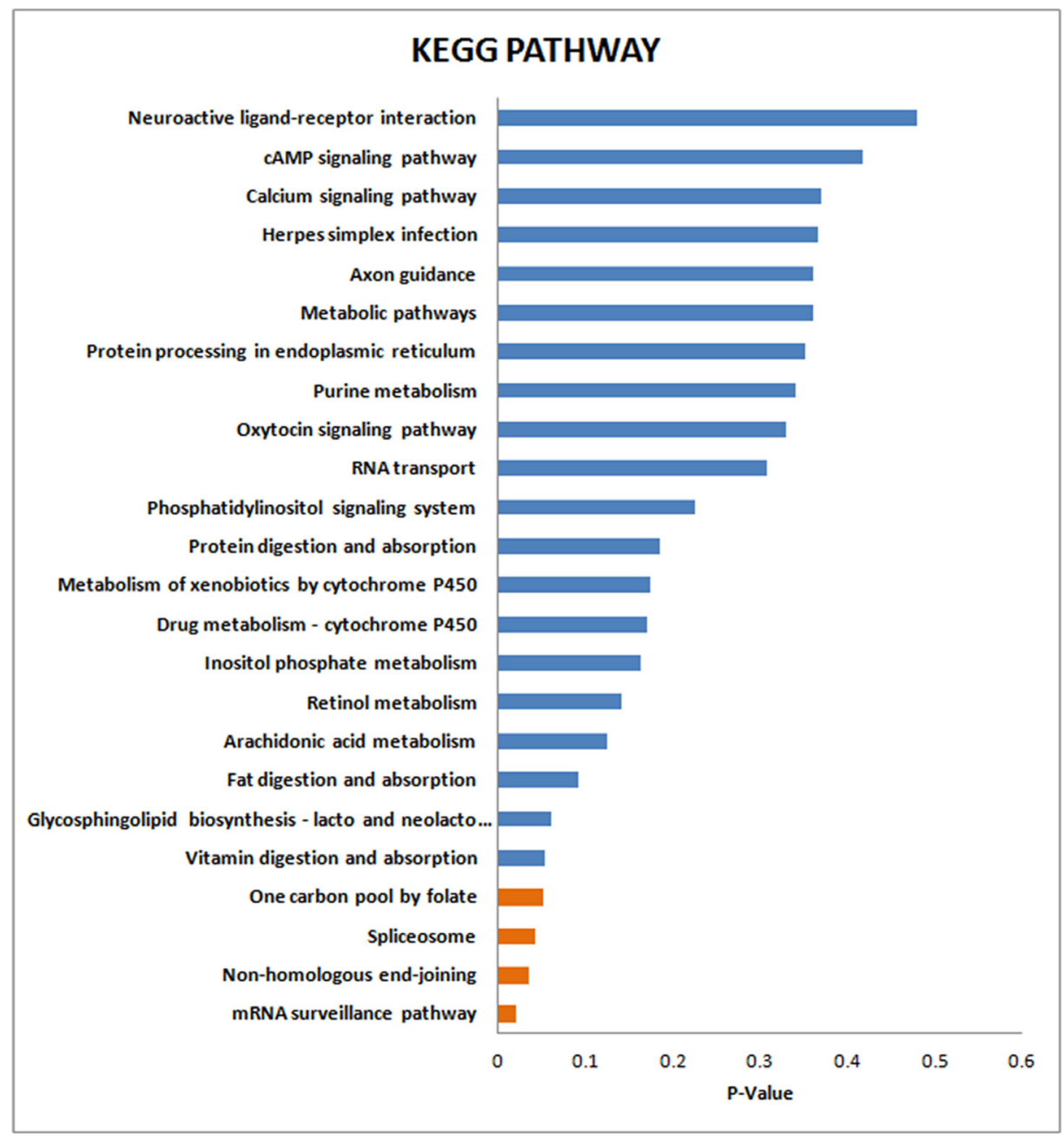

Figure 4: KEGG enrichment analysis of the differentially expressed proteins. 
indicative of MTB infection, we first selected specific proteins whose expression was markedly different in ATB or LTBI groups compared with controls (the IDC and HC groups). Among these proteins, 49 were differentially expressed between LTBI and ATB. These proteins were further performed by volcano plot. The traditional volcano plot is a combination of fold change and t-tests. Note, for unpaired samples, the $\mathrm{x}$-axis is $\log (\mathrm{FC})$. Y-axis is $-\log 10$ ( $P$-value) for both cases, and can be based on raw or FDR adjusted $P$ values. However, our data alignment strategy is: disease control and normal control, respectively, compared with ATB and LTBI, followed look at the difference between the significant difference between the part of ATB and LTBI. In our data, the three biological repetitions and three technical repetitions combined after the comparison, so cannot achieve the traditional meaning of the volcano show. Figure 2B just showed the different proteins between ATB and LTBI.

These plasma proteins were further subjected to a GO enrichment analysis which clustered proteins based on three defined ontology terms: GO-CC, GO-BP and GOMF [22]. Here, we observed that most of these proteins were present in the isolated cell or organelle fraction. Similarly, released intracellular proteins were detected in MTB-infected plasma, suggesting the importance of these associated proteins at the lesions created by MTB infection. In addition, other identified proteins were associated with protein binding. These results demonstrate that the proteins affecting the MTB infection status were related to DNA and protein binding, cellular and metabolic processes.

Among the 49 differentially expressed proteins, XRCC4, PCF11, SEMA4A and ATP11A were selected for further validation. The above functional analysis demonstrated that most different proteins influencing the MTB infection status were mainly related to binding, cellular and metabolic processes. The four selected proteins were all associated with these processes. It is well known that binding is the first step of the MTB infection and these four selected proteins were all participate in the binding process, including nucleic acid binding and protein binding. Furthermore, MTB infection also changes metabolic processes. XCRR4 and PCF11 influence metabolic processes and were significantly different between the ATB and LTBI groups. According to the GO analysis, SEMA4A and ATP11A, which are related to cellular processes, also had an important role in MTB infection.

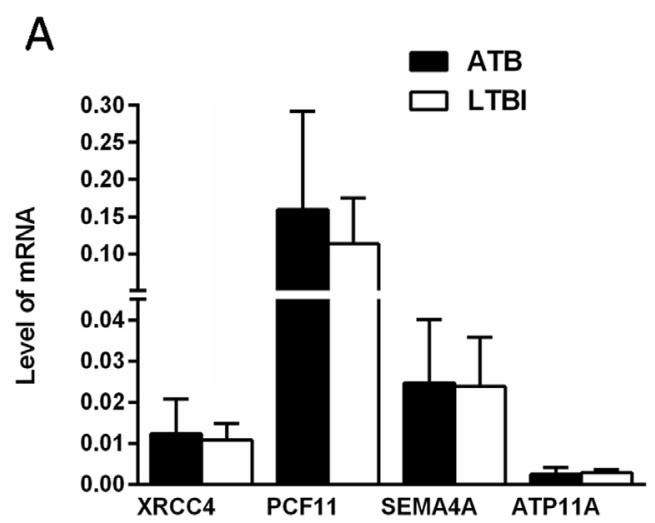

C

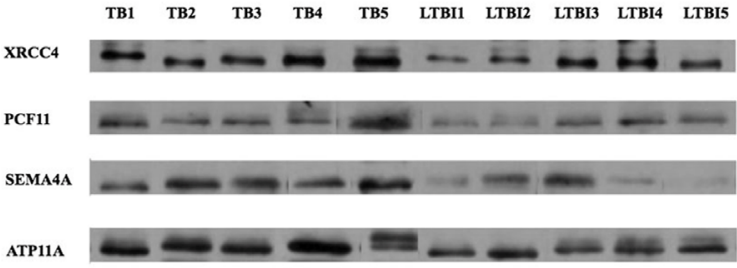

B

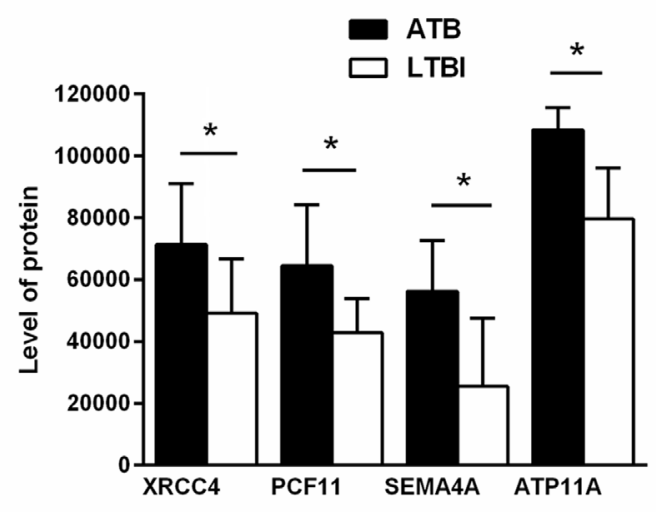

D

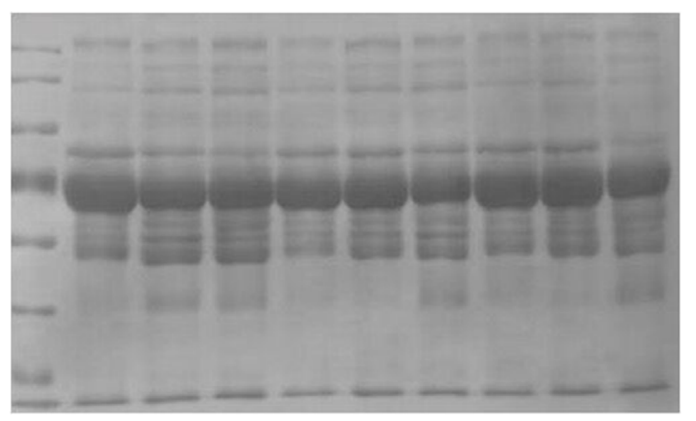

Figure 5: Verification of up- or down-regulated proteins between ATB and LTBI. (A) RT-PCR analysis data of four selected proteins in the PBMCs of ATB patients compared with that of LTBI patients $\left(\mathrm{n}_{\text {ATB }}=28, \mathrm{n}_{\text {LTBI }}=18\right)$; data are presented as means \pm SD. (B) The average signals of ATB and LTBI patients group $(P<0.05, \mathrm{n}=5$ per group); data are presented as means \pm SD. (C) Western blot analysis of the four selected proteins from ATB and LTBI subjects ( $\mathrm{n}=5$ per group). (D) Total protein staining by Coomassie Blue employed as the loading control. 
The levels of mRNA after MTB infection did not correlate with the proteins level. A similar result demonstrated that when the most induced proteins in human mesenchymal stromal cells (HMSCs) were assayed by qPCR, the results do not match the results detected by MS [23]. This is a limitation of the current study.

The selected proteins have previously been reported to be associated with immunity and other infectious diseases [24-35]. XRCC4 is an important component of non-homologous end-joining [24]. The expression of this gene is associated with many infectious diseases, including HSV-1 [25, 26]. In addition, PCF11serves as a target for regulated transcription and pre-mRNA processing. Recent studies showed that it is also involved in regulated transcription initiation, elongation, termination and alternative processing of pre-mRNA [27-29]. SEMA4A is expressed by dendritic cells, macrophages, and activated $\mathrm{T}$ cells $[30,31]$. It is involved in co-stimulation in helper $\mathrm{T}$ cell proliferation and cytokine production [32, 33]. Higher levels of SEMA4A in ATB group implied the higher T cell activation in MTB infection than in LTBI. ATP11A, a member of P4-ATPases, is a lipid flippase [34]. A previous study demonstrated that lipid flippases are essential to mediate the endotoxin-induced endocytosis of Toll-like receptor 4 in human macrophages. Macrophages play a primary role in TB transmission [35]. MTB usually replicates within macrophages and spreads to pulmonary lymph nodes. Furthermore, lipid flippase is also important to dampen the inflammatory response, implying that ATP11A had an important effect in MTB infection. Our results indicate, for the first time, that the expression of these proteins were also correlated with the conversion from LTBI to ATB in children.

Because of the difficulty of enrolling LTBI pediatric subjects, a limitation of this study is the relatively small sample size used for verification. Thus, a larger sample size and further mechanism analysis should be the focus of future investigations.

In conclusion, we identified 49 differentially expressed plasma proteins related to the differential status of MTB infection by the label-free quantitative method. After analyzing the protein functions and regulatory networks, XRCC4, PCF11, SEMA4A and ATP11A were selected and further verified by qPCR and western blot. Our results will provide important data for molecular mechanism studies and biomarker selection during MTB infection.

\section{MATERIALS AND METHODS}

\section{Patients and controls}

Respiratory infectious diseases overlapping with TB in children are very common. Therefore, to detect the differences that are indicative of MTB infection, IDC and $\mathrm{HC}$ were also included in this study.
A total of 72 children (19 ATB, 16 LTBI, 17 IDC and $20 \mathrm{HC}$ ) were enrolled at Beijing Children's Hospital between July 2010 to May 2013. The diagnosis of pediatric ATB was according to the guidelines of the Chinese Medical Association: (1) MTB culture result was positive, or (2) at least one symptom, sign, or radiographic evidence was consistent with ATB, or (3) clinical and radiological improvement was seen following anti-TB chemotherapy [2]. To accurately reflect the MTB infection status, all the ATB sera were collected before anti-TB chemotherapy.

LTBI was defined as (1) positive by both IGRAs and TST, (2) exposure history to a known ATB case, (3) no clinical, radiological and microbiological evidence of active TB [36].

IDC group subjects were enrolled according to their respiratory symptoms and negative IGRAs and TST results $(<5 \mathrm{~mm})$ to exclude ATB and LTBI. HC group subjects were recruited from children admitted to Beijing Children's Hospital for physical examination from June 2012 to May 2013. The IDC and HC controls with negative IGRAs and TST results, had not been previously infected with TB, HIV or other infectious diseases. Each group was matched by age, sex, and ethnicity.

At the qPCR verification stage, we utilized the peripheral blood mononuclear cell (PBMC) samples from 28 ATB (18 boys and 10 girls; median age 5.0 years, range 0.4-12 years) and 18 age- and gender-matched LTBI subjects( 12 boys and 6 girls; median age 5.6 years, range $0.25-15$ years). At the western blot verification stage, the plasma of 5 ATB ( 3 boys and 2 girls; median age 8.3 years, range 3-12 years) and 5 age- and gender-matched LTBI subjects ( 2 boys and 3 girls; median age 7.6 years, range 3-11 years) were collected. The diagnosis criteria of pediatric ATB and LTBI outlined above. All the subjects had the positive IGRAs and TST results.

The study was approved by the Ethics Committee of Beijing Children's Hospital. All the methods and experimental protocols in this research were performed according to the approved protocols and the Ethics Committees' existing guidelines. The parents of all children provided written, informed consent prior to their enrollment in the study.

\section{Protein extraction and digest}

Human plasma samples were pooled for each group and divided into 3 aliquots. Albumin, IgG, IgA, antitrypsin, transferrin and haptoglobin were removed by the Agilent Multiple Affinity Removal Column (Multiple Affinity Removal Column, $4.6 \mathrm{~mm} \times 50 \mathrm{~mm}$; Agilent Technologies, Palo Alto, CA, USA). After being resuspended with PBS $(50 \mu \mathrm{L})$, the samples were centrifuged at $10,000 \mathrm{~g}$ for $30 \mathrm{~min}$ in $4^{\circ} \mathrm{C}$ and resuspended with $100 \mu \mathrm{L}$ lysis buffer (7 M urea, $2 \mathrm{M}$ thiourea). Total proteins were extracted by ultrasonic sonication and 
precipitated with trichloroacetic acid (TCA) for $30 \mathrm{~min}$ on ice before centrifuging at $40,000 \mathrm{~g}$ for $30 \mathrm{~min}$. Next, the protein concentration was adjusted with $50 \mathrm{mM} \mathrm{NH}_{4} \mathrm{HCO}_{3}$ to a final concentration of $0.5 \mathrm{mg} / \mathrm{mL}$ and then mixed with DTT $(5 \mu \mathrm{l}, 1 \mathrm{~mol} / \mathrm{L})$ and incubated at $37^{\circ} \mathrm{C}$ for $60 \mathrm{~min}$. After incubation with IAA $(20 \mu \mathrm{L}, 1 \mathrm{~mol} / \mathrm{L})$ for $60 \mathrm{~min}$ in the dark, the samples were digested with trypsin at $37^{\circ} \mathrm{C}$ for $12 \mathrm{~h}$ [17].

\section{LC-MS/MS analysis}

Peptide mixtures were used for protein identification by nano-liquid chromatography coupled with MS. The LCMS/MS system consisted of an Agilent 1100 quaternary HPLC (EASY-nLC1000) and a micrOTOF-Q II mass spectrometer (Bruker Daltonics, USA) with the application of a distal $180^{\circ} \mathrm{C}$ source temperature. A RP trapcolumn (Thermo EASY column SC200 $150 \mu \mathrm{m} \times 100 \mathrm{~mm}$ ) was used for desalting, and a $\mathrm{C} 18$ reverse-phase column (Thermo EASY column SC001 traps $150 \mu \mathrm{m} \times 20 \mathrm{~mm}$ ) was used for separation. Mobile phase A consisted of HPLC-grade water containing $0.1 \%$ formic acid (FA), and phase $\mathrm{B}$ consisted of $84 \%$ HPLC-grade acetonitrile (ACN) containing $0.1 \% \mathrm{FA}$. The analytical separation was run at a flow rate of $400 \mathrm{nl} / \mathrm{min}$ using a linear gradient of phase B as follows: $0-45 \%$ for $100 \mathrm{~min}, 45-100 \%$ for $8 \mathrm{~min}$ and $100 \%$ for $12 \mathrm{~min}$. To reduce the technical variation the analyses were repeated three times [37]. Peptide spectral matches (PSMs) were validated using the percolator provided by the Proteome Discoverer software based on q-values at a $1 \%$ false discovery rate.

Normalization by a reference sample, also known as probabilistic quotient normalization, is a robust method to account for different dilution effects of biofluids. This method is based on the calculation of a most probable dilution factor (median) by looking at the distribution of the quotients of the amplitudes of a test spectrum by those of a reference spectrum [38].

\section{Bioinformatics analysis}

For protein identification, the Mascot 2.1 program (Matrix Science, Boston, MA, USA) was used for fragmentation spectra research, which was searched against the human database. Two missed cleavages were permitted, and an error of 6 ppm or 20 ppm was allowed for full MS or MS/MS spectra study, respectively. Furthermore, we used the resulting MGF documents and Data Analysis 3.4 from Bruker Daltonics Software to detect the fold-changes of the protein levels of each group. The identified proteins were analyzed by GO categories using the Web Gene Ontology Annotation Plotting (WEGO, http://wego.genomics.org.cn/cgi-bin/wego/index.

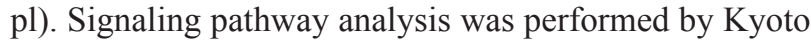
Encyclopedia of Genes and Genome (KEGG) database (http://www.genome.jp/kegg/pathway.html) [39].
Proteins used for validation were selected by molecular function and the biological process or pathway term in PANTHER.

\section{Quantitative real-time PCR}

Total RNA was obtained using miRNeasy Mini Kits (Qiagen, Valencia, CA, USA) according to the manufacturer's instructions. Subsequently, $500 \mathrm{ng}$ of the RNA was reverse transcribed to cDNA using ReverTra Ace qPCR RT Kits(TOYOBO, Osaka, Japan), and quantitative real-time PCR was carried out with a $7900 \mathrm{HT}$ Sequence Detection System (ABI, Foster City, CA, USA) using ABI Power SYBR Green PCR Master Mix. The raw data were normalized using the Quantile algorithm in GeneSpring 11.0 (Agilent Technologies, Santa Clara, CA, USA). The thermal cycling conditions were: $2 \mathrm{~min}$ at $95^{\circ} \mathrm{C}$ for initial denaturation, followed by 40 cycles of $15 \mathrm{sec}$ at $95^{\circ} \mathrm{C}, 60 \mathrm{sec}$ at $60^{\circ} \mathrm{C}$ for amplification, and $15 \mathrm{sec}$ at $95^{\circ} \mathrm{C}, 15 \mathrm{sec}$ at $60^{\circ} \mathrm{C}$ and $15 \mathrm{sec}$ at $95^{\circ} \mathrm{C}$ for melting curve analysis [6]. Target gene primers are listed in Supplementary Table 4.

\section{Western blot}

Western bloting was performed as described previously, with minor differences [6]. Briefly, proteins extracted from plasma, were separated using 12\% SDS-PAGE gels and transferred to PVDF membranes (Millipore, Billerica, MA, USA). For detection, after incubation with primary antibodies overnight at $4{ }^{\circ} \mathrm{C}$, the membranes were washed three times with Tris-buffered saline containing Tween-20 (TBS-T), and incubated with horseradish peroxidase (HRP) - conjugated secondary antibodies (1:5000; Santa Cruz, Dallas, TX, USA) for 2 $\mathrm{h}$ at room temperature. Antibody binding was visualized using the Enhanced Chemi Luminescence Kit (ECL-Kit, Santa Cruz) after being washed in PBS-T. The primary antibodies used in this experiment included rabbit polyclonal anti-XRCC4 antibody (Abcam, Cambridge, MA, USA, diluted 1:1000), rabbit polyclonal antiPCF11 antibody (Abcam, diluted 1:2000), rabbit polyclonal anti-SEMA4A antibody (Abcam, diluted $1: 1000$ ), rabbit polyclonal anti-ATP11A antibody (Santa Cruz, diluted 1:1000), and mouse monoclonal anti- $\beta$ actin antibody (Upstate, Lake Placid, NY, USA; diluted $1: 2000)$.

Ten $\mu \mathrm{g}$ protein was loaded per lane of a 1-mmthick mini polyacrylamide SDS-gel. The proteins were stained with Coomassie Blue as an internal control for normalization [40] Proteins were transferred to a NC membrane for $1 \mathrm{~h}$ using Bio-rad Trans-Blot. After being blocked with $3 \% \mathrm{BSA}$ for $30 \mathrm{~min}$, the target proteins were incubated with primary antibody and associated secondary to each blot with at least four, 3-minute wash steps. 


\section{Statistical analysis}

Each experiment was repeated independently at least three times. Data are expressed as the mean $\pm \mathrm{SD}$ and differences between groups were evaluated with the Student t-test or Mann-Whitney U test. Values of $P<0.05$ were considered statistically significant.

\section{ACKNOWLEDGMENTS}

We are grateful to all our study participants.

\section{CONFLICTS OF INTEREST}

The authors have declared no conflicts of interest.

\section{GRANT SUPPORT}

This work was supported by grants from Beijing Natural Science Foundation (No. 7164257 and No. 7163214), the BeiJing Talent Fund (No.2014000021469G244), Capital Health Research and Development of Special Grant (No. 2016-1-2092).

\section{REFERENCES}

1. Murray CJ, Ortblad KF, Guinovart C, Lim SS, Wolock TM, Roberts DA, Dansereau EA, Graetz N, Barber RM, Brown JC, Wang H, Duber HC, Naghavi M, et al. Global, regional, and national incidence and mortality for HIV, tuberculosis, and malaria during 1990-2013: a systematic analysis for the Global Burden of Disease Study 2013. Lancet. 2014; 384:1005-70.

2. Shen C, Qi H, Sun L, Xiao J, Yin QQ, Jiao WW, Wu XR, Tian JL, Han R, Shen AD. A 3'UTR Polymorphism of IL-6R Is Associated with Chinese Pediatric Tuberculosis. Biomed Res Int. 2014; 2014:483759.

3. Newton SM, Brent AJ, Anderson S, Whittaker E, Kampmann B. Paediatric tuberculosis. Lancet Infect Dis. 2008; 8:498-510.

4. Liu J, Jiang T, Wei L, Yang X, Wang C, Zhang X, Xu D, Chen Z, Yang F, Li JC. The discovery and identification of a candidate proteomic biomarker of active tuberculosis. BMC Infect Dis. 2013; 13:506.

5. Xu D, Li Y, Li X, Wei LL, Pan Z, Jiang TT, Chen ZL, Wang C, Cao WM, Zhang X, Ping ZP, Liu CM, Liu JY, et al. Serum protein S100A9, SOD3, and MMP9 as new diagnostic biomarkers for pulmonary tuberculosis by iTRAQ-coupled two-dimensional LC-MS/MS. Proteomics. 2015; 15:58-67.

6. Li S, Li X, Wang Y, Yang J, Chen Z, Shan S. Global secretome characterization of A549 human alveolar epithelial carcinoma cells during Mycoplasma pneumoniae infection. BMC Microbiol. 2014; 14:27.
7. Flores-Villalva S, Rogríguez-Hernández E, RubioVenegas Y, Cantó-Alarcón JG, Milián-Suazo F. What Can Proteomics Tell Us about Tuberculosis? J Microbiol Biotechnol. 2015; 25:1181-94.

8. Agranoff D, Fernandez-Reyes D, Papadopoulos MC, Rojas SA, Herbster M, Loosemore A, Tarelli E, Sheldon J, Schwenk A, Pollok R, Rayner CF, Krishna S. Identification of diagnostic markers for tuberculosis by proteomic fingerprinting of serum. Lancet. 2006; 368:1012-21.

9. Hodgetts A, Levin M, Kroll JS, Langford PR. Biomarker discovery in infectious diseases using SELDI. Future Microbiol. 2007; 2:35-49.

10. Papadopoulos MC, Abel PM, Agranoff D, Stich A, Tarelli E, Bell BA, Planche T, Loosemore A, Saadoun S, Wilkins P, Krishna S. A novel and accurate diagnostic test for human African trypanosomiasis. Lancet. 2004; 363:1358-63.

11. Ren Y, He QY, Fan J, Jones B, Zhou Y, Xie Y, Cheung CY, Wu A, Chiu JF, Peiris JS, Tam PK. The use of proteomics in the discovery of serum biomarkers from patients with severe acute respiratory syndrome. Proteomics. 2004; $4: 3477-84$.

12. Zhang X, Guo T, Wang H, He W, Mei H, Hong M, Yu J, Hu Y, Song S. Potential biomarkers of acute cerebral infarction detected by SELDI-TOF-MS. Am J Clin Pathol. 2008; 130:299-304.

13. Hong M, Zhang X, Hu Y, Wang H, He W, Mei H, Yu J, Guo $\mathrm{T}$, Song $\mathrm{S}$. The potential biomarkers for thromboembolism detected by SELDI-TOF-MS. Thromb Res. 2009; 123:556-64.

14. Pinet F, Beseme O, Cieniewski-Bernard C, Drobecq H, Jourdain S, Lamblin N, Amouyel P, Bauters C. Predicting left ventricular remodeling after a first myocardial infarction by plasma proteome analysis. Proteomics. 2008; 8:1798-808.

15. Engwegen JY, Gast MC, Schellens JH, Beijnen JH. Clinical proteomics: searching for better tumour markers with SELDI-TOF mass spectrometry. Trends Pharmacol Sci. 2006; 27:251-59.

16. Ligon LS, Hayden JD, Braunstein M. The ins and outs of Mycobacterium tuberculosis protein export. Tuberculosis (Edinb). 2012; 92:121-32.

17. Zhang J, Wu X, Shi L, Liang Y, Xie Z, Yang Y, Li Z, Liu C, Yang F. Diagnostic serum proteomic analysis in patients with active tuberculosis. Clin Chim Acta. 2012; 413:883-87.

18. Sinha S, Kosalai K, Arora S, Namane A, Sharma P, Gaikwad AN, Brodin P, Cole ST. Immunogenic membraneassociated proteins of Mycobacterium tuberculosis revealed by proteomics. Microbiology. 2005; 151:2411-19.

19. Matsuzawa Y. Therapy Insight: adipocytokines in metabolic syndrome and related cardiovascular disease. Nat Clin Pract Cardiovasc Med. 2006; 3:35-42. 
20. Miettinen JJ, Matikainen S, Nyman TA. Global secretome characterization of herpes simplex virus 1-infected human primary macrophages. J Virol. 2012; 86: 12770-12778.

21. Mason GM, Poole E, Sissons JG, Wills MR, Sinclair JH. Human cytomegalovirus latency alters the cellular secretome, inducing cluster of differentiation (CD)4+ T-cell migration and suppression of effector function. Proc Natl Acad Sci USA. 2012; 109:14538-43.

22. Barrell D, Dimmer E, Huntley RP, Binns D, O’Donovan C, Apweiler R. The GOA database in 2009 — an integrated Gene Ontology Annotation resource. Nucleic Acids Res. 2009; 37:D396-403.

23. da Costa MR, Pizzatti L, Lindoso RS, Sant'Anna JF, DuRocher B, Abdelhay E, Vieyra A. Mechanisms of kidney repair by human mesenchymal stromal cells after ischemia: a comprehensive view using label-free MS(E). Proteomics. 2014; 14:1480-93.

24. Mari PO, Florea BI, Persengiev SP, Verkaik NS, Brüggenwirth HT, Modesti M, Giglia-Mari G, Bezstarosti K, Demmers JA, Luider TM, Houtsmuller AB, van Gent DC. Dynamic assembly of end-joining complexes requires interaction between Ku70/80 and XRCC4. Proc Natl Acad Sci USA. 2006; 103:18597-602.

25. Muylaert I, Elias P. Knockdown of DNA ligase IV/XRCC4 by RNA interference inhibits herpes simplex virus type I DNA replication. J Biol Chem. 2007; 282:10865-72.

26. Jayaram S, Gilson T, Ehrlich ES, Yu XF, Ketner G, Hanakahi L. E1B 55k-independent dissociation of the DNA ligase IV/XRCC4 complex by E4 34k during adenovirus infection. Virology. 2008; 382:163-70.

27. Klatt A, Zhang Z, Kalantari P, Hankey PA, Gilmour DS, Henderson AJ. The receptor tyrosine kinase RON represses HIV-1 transcription by targeting RNA polymerase II processivity. J Immunol. 2008; 180:1670-77.

28. Loya TJ, O'Rourke TW, Reines D. A genetic screen for terminator function in yeast identifies a role for a new functional domain in termination factor Nab3. Nucleic Acids Res. 2012; 40:7476-91.

29. Xing D, Wang Y, Xu R, Ye X, Yang D, Li QQ. The regulatory role of Pcf11-similar-4 (PCFS4) in Arabidopsis development by genome-wide physical interactions with target loci. BMC Genomics. 2013; 14:598.

30. Kumanogoh A, Marukawa S, Suzuki K, Takegahara N, Watanabe C, Ch'ng E, Ishida I, Fujimura H, Sakoda S, Yoshida K, Kikutani H. Class IV semaphorin Sema4A enhances T-cell activation and interacts with Tim-2. Nature. 2002; 419:629-33.
31. Meda C, Molla F, De Pizzol M, Regano D, Maione F, Capano S, Locati M, Mantovani A, Latini R, Bussolino F, Giraudo E. Semaphorin 4A exerts a proangiogenic effect by enhancing vascular endothelial growth factor-A expression in macrophages. J Immunol. 2012; 188:4081-92.

32. Kumanogoh A, Shikina T, Suzuki K, Uematsu S, Yukawa K, Kashiwamura S, Tsutsui H, Yamamoto M, Takamatsu H, Ko-Mitamura EP, Takegahara N, Marukawa S, Ishida I, et al. Nonredundant roles of Sema4A in the immune system: defective $\mathrm{T}$ cell priming and $\mathrm{Th} 1 / \mathrm{Th} 2$ regulation in Sema4A-deficient mice. Immunity. 2005; 22:305-16.

33. Leitner DF, Todorich B, Zhang X, Connor JR. Semaphorin4A Is Cytotoxic to Oligodendrocytes and Is Elevated in Microglia and Multiple Sclerosis. ASN Neuro. 2015; 7:7.

34. Miyoshi N, Ishii H, Mimori K, Tanaka F, Nagai K, Uemura M, Sekimoto M, Doki Y, Mori M. ATP11A is a novel predictive marker for metachronous metastasis of colorectal cancer. Oncol Rep. 2010; 23:505-10.

35. van der Mark VA, Ghiboub M, Marsman C, Zhao J, van Dijk R, Hiralall JK, Ho-Mok KS, Castricum Z, de Jonge WJ, Oude Elferink RP, Paulusma CC. Phospholipid flippases attenuate LPS-induced TLR4 signaling by mediating endocytic retrieval of Toll-like receptor 4 . Cell Mol Life Sci. 2017; 74:715-30.

36. Zhang X, Liu F, Li Q, Jia H, Pan L, Xing A, Xu S, Zhang Z. A proteomics approach to the identification of plasma biomarkers for latent tuberculosis infection. Diagn Microbiol Infect Dis. 2014; 79:432-37.

37. Lee J, Kim SH, Choi DS, Lee JS, Kim DK, Go G, Park SM, Kim SH, Shin JH, Chang CL, Gho YS. Proteomic analysis of extracellular vesicles derived from Mycobacterium tuberculosis. Proteomics. 2015; 15:3331-37.

38. Dieterle F, Ross A, Schlotterbeck G, Senn H. Probabilistic quotient normalization as robust method to account for dilution of complex biological mixtures. Application in $1 \mathrm{H}$ NMR metabonomics. Anal Chem. 2006; 78:4281-90.

39. Kanehisa M, Goto S, Kawashima S, Okuno Y, Hattori M. The KEGG resource for deciphering the genome. Nucleic Acids Res. 2004; 32:D277-80.

40. Fischle W, Tseng BS, Dormann HL, Ueberheide BM, Garcia BA, Shabanowitz J, Hunt DF, Funabiki H, Allis CD. Regulation of HP1-chromatin binding by histone H3 methylation and phosphorylation. Nature. 2005; 438:1116-22. 